\title{
Pulmonary blastoma with diverse mesenchymal proliferation
}

\author{
M. RAY CHA U DHURI, W. N. EASTHAM, and \\ P. A. F R E D R I K S Z \\ Department of Morbid Anatomy and Thoracic Surgery, Medical Faculty of Rotterdam,
The Netherlands
}

\begin{abstract}
Pulmonary blastomas are extremely rare subpleural tumours consisting of relatively welldifferentiated branched tubular glands which resemble fetal lung tissue embedded in a malignant mesodermal stroma. The previous 13 established cases reported up to June 1969 are now supplemented by a fourteenth. The patient was a 32-year-old man who developed acute pain in the right chest followed by a haemorrhagic pleural effusion. At thoracotomy a yellowishwhite necrotic and vascular tumour was located lying loosely in the fissure between the upper and the middle lobes. The histological appearance of the tumour was unusual in that the mesodermal element was very variable and in different areas simulated fibrosarcoma, leiomyosarcoma, lipomyxosarcoma, and malignant haemangiopericytoma. This diversity of mesodermal proliferation is best explained on the basis that the tumour has originated in an embryonic or pleuripotential type of mesenchyme, the site of which is probably in the periphery of the lung.
\end{abstract}

Pulmonary blastomas are rare tumours which are frequently large and located subpleurally. Macroscopically, they are often round tumours, creamyyellow in colour, have a soft, friable consistency, and contain extensive areas of haemorrhage and necrosis. Microscopically, they consist of relatively well-differentiated branched tubular glands which resemble fetal lung embedded in a malignant mesodermal stroma. Since Barnard's first description in 1952, 13 similar neoplasms have been reported in the literature (Barson, Jones, and Lodge, 1968). The fourteenth case of pulmonary blastoma was unique in that a variety of metastatic carcinomatous patterns were observed in different organs (Ray Chaudhuri and Winstanley, 1969). This is in marked contrast to the case presented here which showed a diverse mesenchymal differentiation, simulating in various areas fibrosarcoma, leiomyosarcoma, myxoliposarcoma, and malignant haemangiopericytoma.

\section{CASE REPORT}

J.E., a 32-year-old chemical factory supervisor, who had smoked 15 cigarettes a day for the last 15 years, was admitted with a high temperature, severe rightsided chest pain, and dyspnoea. The chest pain had been present for the previous two years but was not localized to any particular area and was of an intermittent and throbbing nature. The chest radiograph at that time was normal, as was a repeat examination a year later. However, on admission the chest radiograph revealed a diffuse opacity over the whole right chest. Aspiration yielded one litre of blood. Tomography, bronchography, sputum cytology, and an open thoracic biopsy failed to establish a definitive diagnosis. A provisional diagnosis of sarcoma was made.

A thoracotomy was performed within one month of admission and revealed a yellowish-white vascular tumour, $10 \times 8 \times 3 \mathrm{~cm}$ in diameter, within the pleural cavity. A total of $400 \mathrm{~g}$ of necrotic haemorrhagic friable material was removed. The tumour was located in the fissure between the upper and lower lobes of the right lung on the posterodorsal aspect. It was seen to lie loosely in the pleural space but did not appear to have infiltrated the chest wall or the adjacent visceral pleura ; it was easily removed.

Postoperatively the patient recovered well. His right lung, which was previously compressed, became fully expanded and the chest pain lessened. A repeat chest film revealed adequate aeration and no opacity.

HISTOPATHOLOGY Examination of the sections revealed the presence of a highly cellular tumour with much mitotic activity. The appearance of the tumour was very variable. In some areas there was prominent whorling and pallisading of spindle cells in the manner of a fibrosarcoma. In other areas the cells were more rounded and grouped together in interlacing bundles, suggesting a leiomyosarcomatous lesion (Fig. 1). These two patterns predominated throughout the tumour 


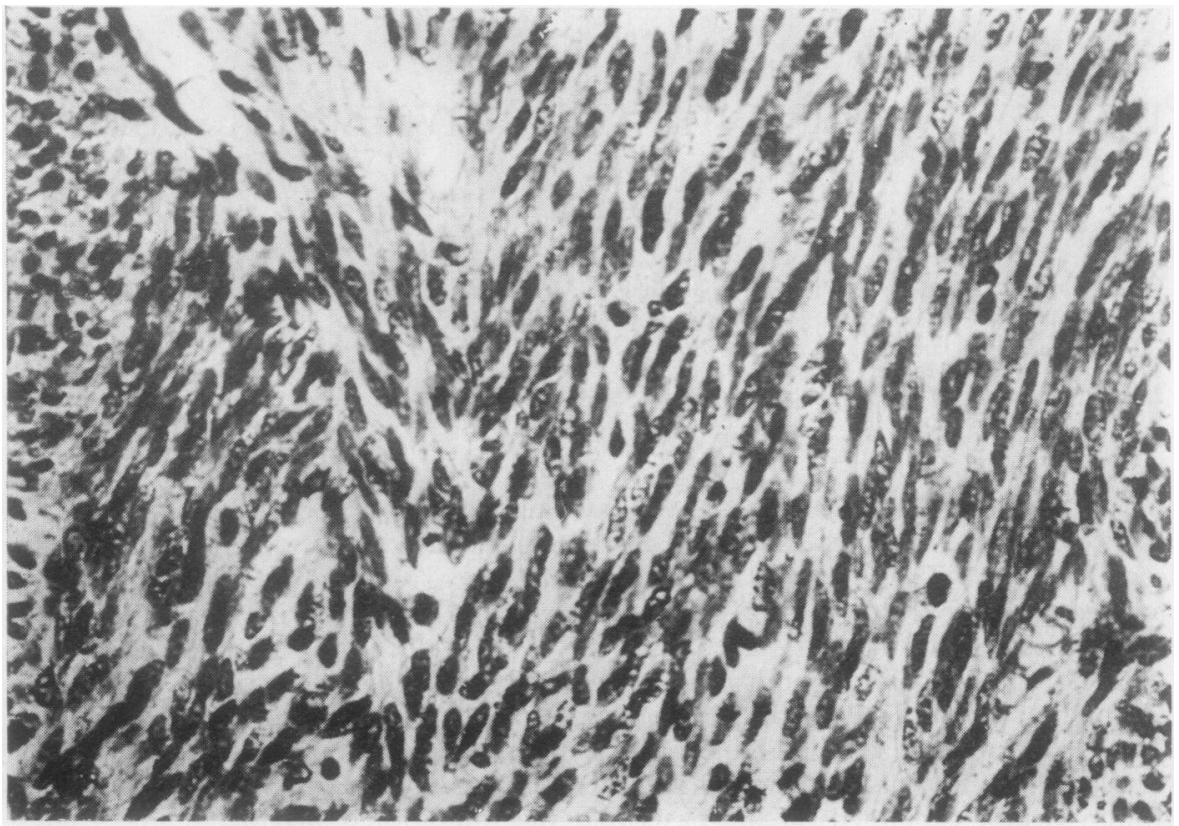

FIG. 1. Spindle-cell pattern from an area simulating both fibrosarcoma and leiomyosarcoma.

Haematoxylin and eosin $\times 385$.

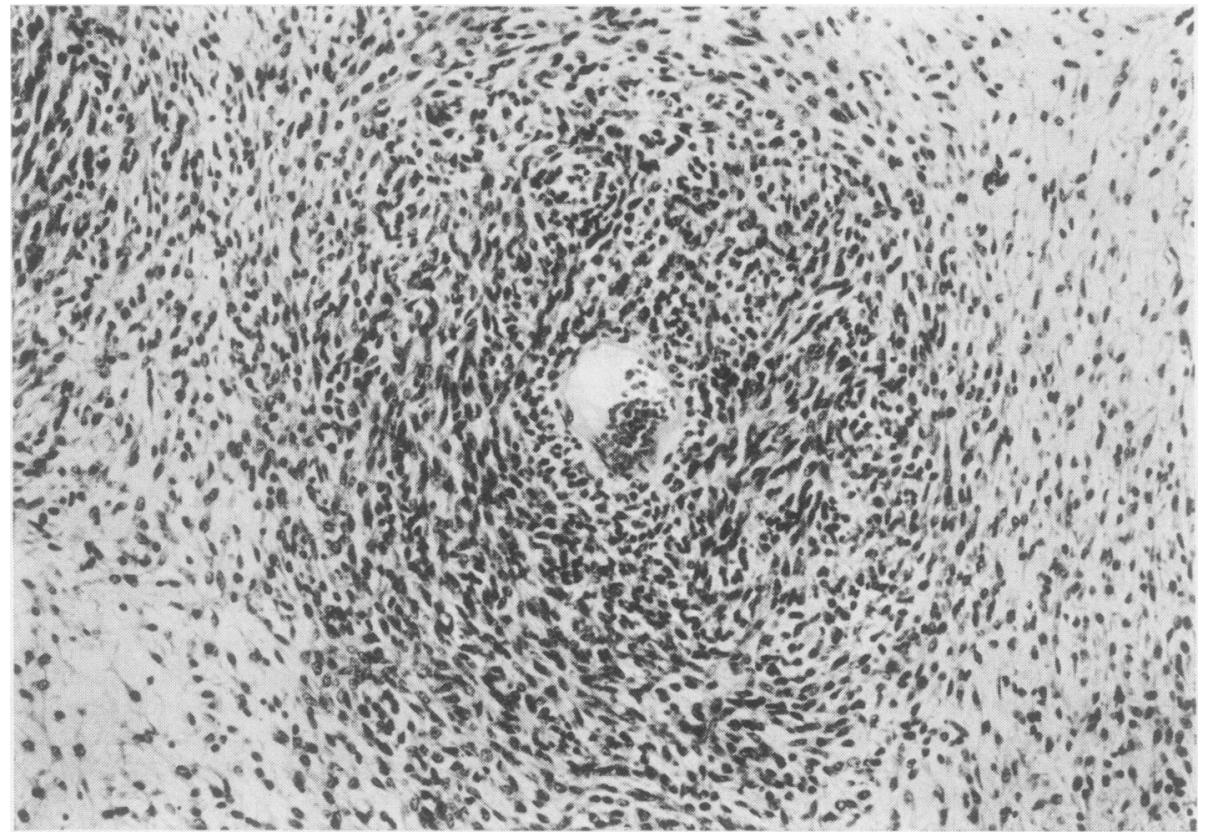

FIG. 2. Spindle cells radiating from perivascular tissue in an area simulating malignant haemangiopericytoma. $H$. and $E . \times 110$. 


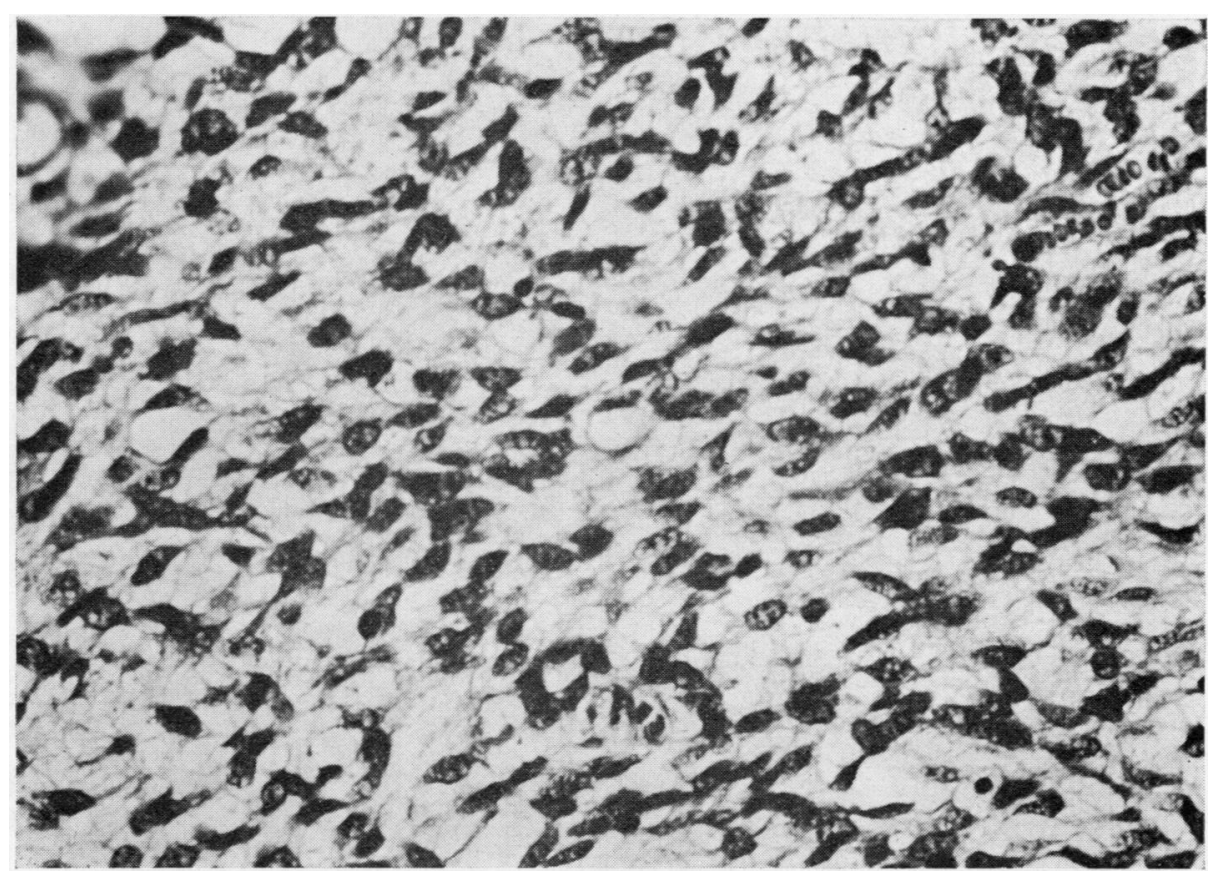

FIG. 3. Lipoblastomatous-like appearance in an area simulating lipomyxosarcoma. $H$. and $E . \times 385$.

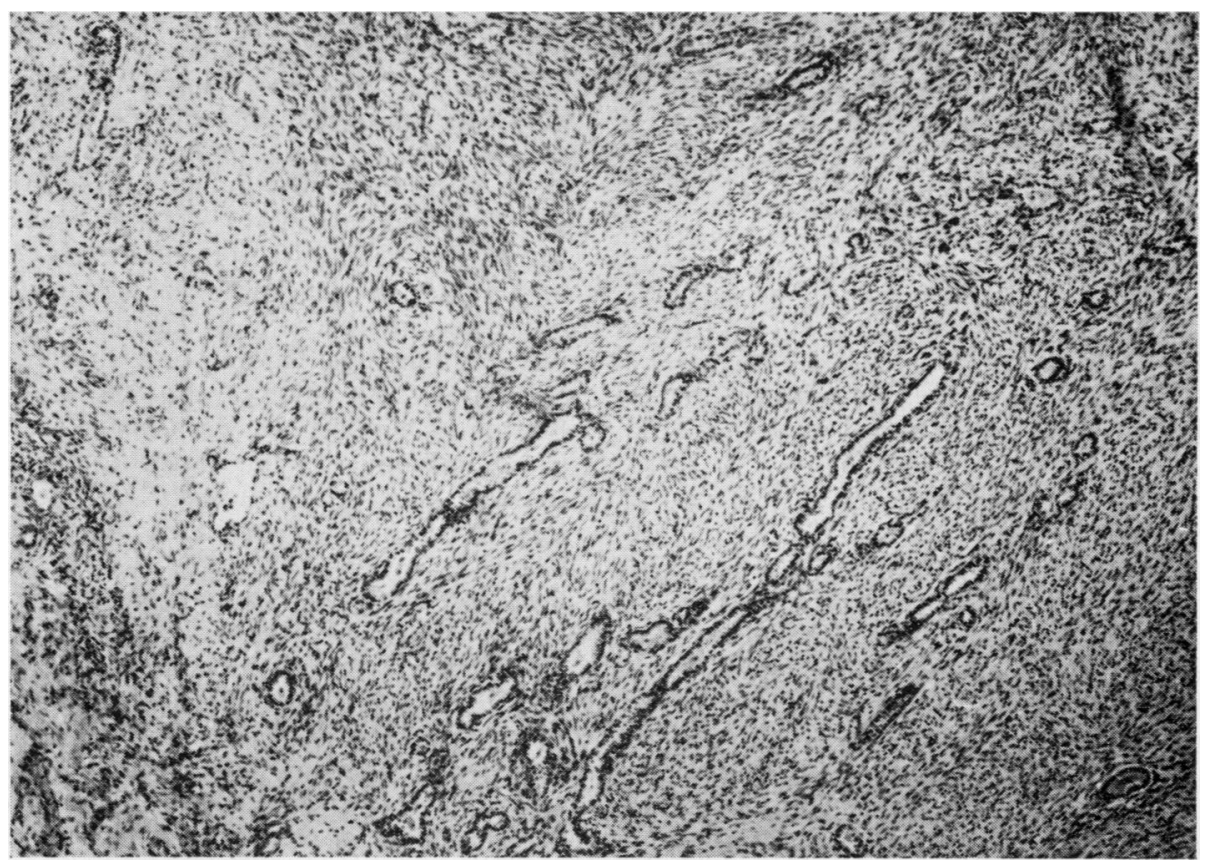

FIG. 4. Branching epithelial tubules in the malignant mesodermal stroma. H. and E. $\times 54$. 


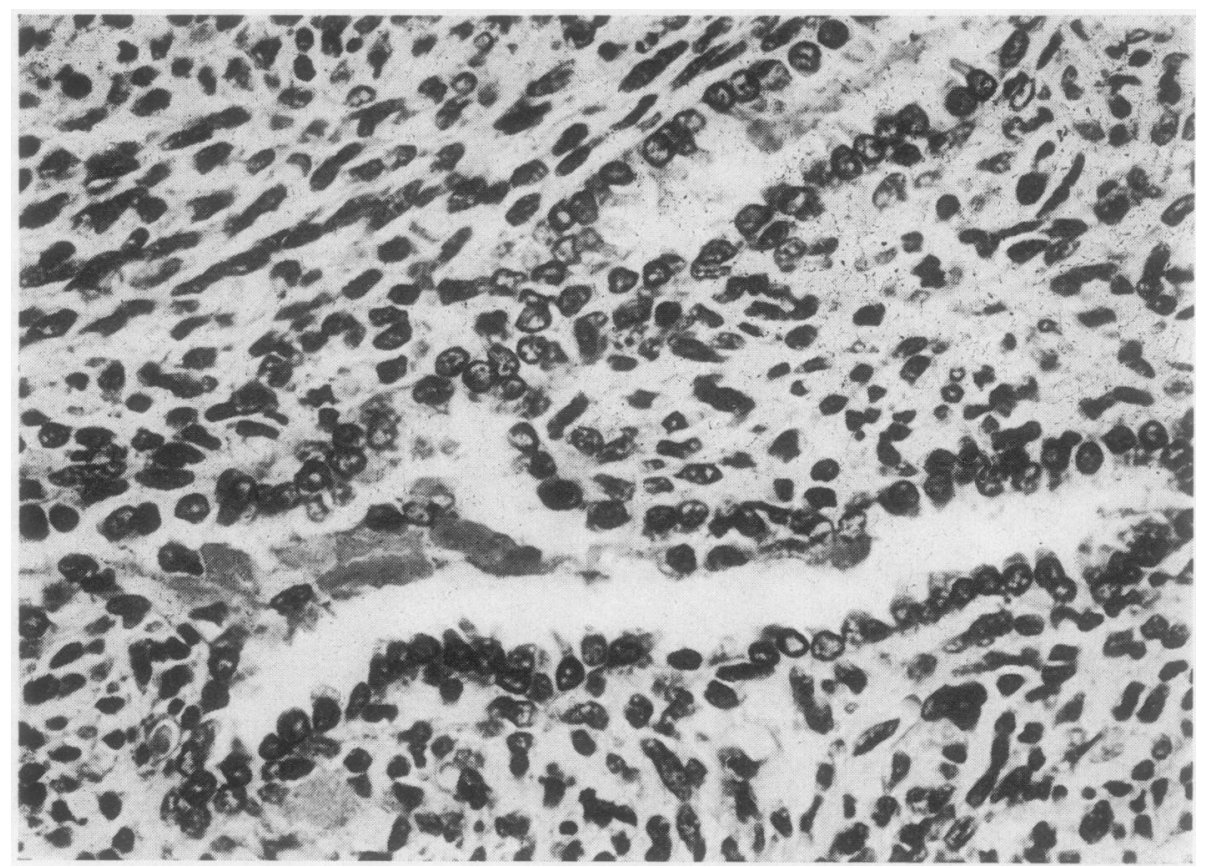

FIG. 5. High-power view of Fig. 4 demonstrating the fetal lung-like appearance of the lining epithelium. $H$. and $E$. $\times 450$.

which was also very vascular. In places the round cells were grouped around thin-walled blood vessels with which they were intimately associated, thus simulating malignant haemangiopericytoma (Fig. 2). The reticulin pattern was also consistent with the diagnosis. In addition there were areas of myxomatous change and areas of liposarcomatous characteristics (Fig. 3). Special stains for collagen and fat were both negative. Finally, the presence of glandular structures lined by cuboidal cells and clearly part of the malignant process were observed (Figs. 4 and 5). On the basis of these histopathological observations, the diagnosis of pulmonary blastoma with a predominantly mesenchymal type of differentiation was made.

\section{DISCUSSION}

The name 'pulmonary blastoma' was first used by Spencer in 1961 for the reason that it had features in common with a nephroblastoma. This term has since been justified by the acceptance of Waddell's (1949) theory of mesenchymal pleuripotentiality. On the basis of transplantation experiments, he was able to show in mice and guineapigs that the periphery of the lung is derived totally from mesenchyme; the canalization of the cords of the mesenchyme leads to the formation of distal air passages which then anastomose with the proliferating lung buds. However, the generally accepted theory of lung embryogenesis maintains that the lung parenchyma is formed from two germ layers, the proliferating endodermal lung buds of primitive foregut becoming invested peripherally by mesoderm (Hamilton, Boyd, and Mossman, 1962). If this alternative explanation of lung embryogenesis is accepted, then the views of Souza, Peasley, and Takaro (1965), Bauermeister, Jennings, Beland, and Judson (1966) and Barson et al. (1968), who dismiss pulmonary blastomas simply as variations of pulmonary carcinosarcomas having a fortuitous resemblance to fetal lung, can be upheld. Of the 30 carcinosarcomas so far reported in the literature (Ray Chaudhuri, 1971), the epithelial element, in all but three of them, was a keratinizing squamouscell carcinoma. In the remaining three cases, the epithelium, though adenomatous, in no way resembled fetal lung. The stroma in all of these tumours was of a fibrosarcomatous nature, four of which showed cartilagenous and bony maturation. To our knowledge, no other sarcomatous elements have ever been demonstrated. Therefore, the characteristics of the tumour presented in this 
paper and of other established cases of pulmonary blastoma are different from those of pulmonary carcinosarcoma in that the blastoma possesses an epithelial element which is both adenomatous and resembles fetal lung and also displays various types of epithelial and mesenchymal differentiation. This was borne out by our previous report (Ray Chaudhuri and Winstanley, 1969) which described an extreme proliferation of epidermal elements when three distinct kinds of carcinomatous metastases (oat-cell, squamous-cell, and giant-cell) were observed in different organs. In the present case, the tumour displayed a definite tendency towards malignant mesenchymal proliferation, and in the variably differentiated embryonic mesenchyme the tubular elements (lined by cuboidal and tall columnar epithelium) have the appearance of fetal lung tissue. This diversification of sarcomatous proliferation in a single pulmonary tumour is extremely unusual and can only be explained by supporting the view that the tumour is an embryonic neoplasm consisting of pleuripotential cells, the site of which is in the periphery of the lung.
The authors wish to thank Dr. C. de Langen for permission to publish the case report. Our thanks are also due to W. M. G. van Harst-Kamp-Roodbeen for the illustrations.

\section{REFERENCES}

Barnard, W. G. (1952). Embryoma of lung. Thorax, 7, 299.

Barson, A. J., Jones, A. W., and Lodge, K. V. (1968). Pulmonary blastoma. J. clin. Path., 21, 480.

Bauermeister, D. E., Jennings, E. R., Beland, A. H., and Judson, H. A. (1966). Pulmonary blastoma-a form of carinosarcoma. Amer. J. clin. Path., 46, 322.

Hamilton, W. J., Boyd, J. D., and Mossman, H. W. (1962). Human Embryology, 3rd ed., p. 230. Heffer, Cambridge.

Ray Chaudhuri, M. (1971). Bronchial carcinosarcoma. $J$. thorac. cardiovasc. Surg., 61, 319.

_ and Winstanley, D. P. (1969). Pulmonary blastoma with diverse metastases. J. Path., 98, 81.

Souza, R. C., Peasley, E. D., and Takaro, T. (1965). Pulmonary blastomas - a distinctive group of carcinosarcomas of the lung. Ann. thorac. Surg., 1, 259.

Spencer, H. (1961). Pulmonary blastomas. J. Path. Bact., 82, 161.

Waddell, W. R. (1949). Organoid differentiation of the foetal lung; histologic study of the differentiation of mammalian foetal lung in utero and in transplants. Arch. Path., 47, 227. 